\title{
Gambaran Dukungan dan Peran Keluarga sebagai PMO dalam Pencegahan TB MDR di Wilayah Kerja Puskesmas Gang Kelor Kota Bogor
}

\author{
${ }^{1}$ Prodi Keperawatan Bogor Poltekkes Kemenkes Bandung \\ Email :indrisil96@gmail.com
}

\begin{abstract}
ABSTRAK
Tuberkulosis merupakan kedaruratan global bagi kemanusiaan, tidak ada satupun negara yang terbebas dari Tuberkulosis. Ketidakpatuhan penderita TB merupakan salah satu hambatan yang ditemui dalam proses pemberantasan penyakit TB. Ketidakpatuhan terhadap pengobatan akan mengakibatkan tingginya angka kegagalan pengobatan atau Tuberkulosis Multi Drug Resisten (TB MDR). Suatu tindakan yang serius yang dapat dilakukan untuk mencegah terjadinya TB MDR yaitu dengan suatu pengawasan terhadap kepatuhan minum obat. Dukungan dan peran dari keluarga sangat berperan penting dalam proses penyembuhan penyakit Tuberkulosis. Oleh karena itulah peneliti tertarik untuk mengambil judul Gambaran Dukungan Dan Peran Keluarga Sebagai PMO Dalam Mencegah TB MDR. Tujuan penelitian ini untuk mengetahui gambaran dukungan dan peran keluarga sebagai PMO dalam mencegah TB MDR. Penelitian ini menggunakan desain penelitian deskriptif. Penelitian ini dilakukan di wilayah kerja Puskesmas Gang Kelor Kota Bogor. Dengan jumlah sampel adalah total populasi yaitu sebanyak 35 responden. Peneliti menggunakan kuesioner yang dibuat sendiri dan dikembangkan dari penelitian Suwardiman (2011), kemudian disesuaikan dengan konsep dan teori yang telah di uraikan pada tinjauan pustaka. Hasil penelitian yaitu lebih dari setengah responden yaitu 18 orang (51\%) memberikan dukungan yang baik sebagai PMO dan lebih dari setengah responden yaitu 20 orang (57\%) berperan dengan baik sebagai PMO dalam mencegah TB MDR.
\end{abstract}

\section{ABSTRACT}

Tuberculosis is a global warning for humanity, none any country could avoid it. One thing that makes TB diseases hard to be vanished is the disobedience of TB patients. Indiscipline in medical treatments will increase the failure that used to call Multi Drug resistant Tuberculosis (MDR TB). A serious control in medical treatment of patients would restrain the TB MDR happen. Family has an important role to support the recovery of TB patients. Therefore, the writer or researcher id interested in taking the research entitled "The Description of Family Role and Support as PMO in preventing MDR TB". This study uses descriptive research design. This research was conducted in Gang Kelor Kota Bogor working area with 35 respondents of total populations as samples. This study uses selfmade questionnairs and developed by Suwardiman (2011), and adjusted to the concepts and theories that have been described in Literature Review. The result of this study shows that more than half of respondents 18 persons (51\%) giving good support as POM and more than half of respondents 20 persons (57\%) have good role as PMO in preventing TB MDR.

Keywords: TB, PMO, Family Support, Family Role 


\section{PENDAHULUAN}

Tuberkulosis adalah penyakit infeksi saluran nafas bawah yang disebabkan oleh mikroorganisme Mycobacterium Tuberculosis, yang biasanya ditularkan melalui droplet. Apabila Tuberkulosis tidak diobati, $50 \%$ dari klien Tuberkulosis akan meninggal setelah 5 tahun. ${ }^{1}$ Menurut WHO tahun 2013 diperkirakan terdapat 8,6 juta kasus Tuberkulosis. WHO merekomendasikan strategi Directly Observed Treatment Shortcourse (DOTS) sebagai salah satu strategi dalam penanggulangan Tuberkulosis yang diperkenalkan pada tahun 1990an.

Di Indonesia, prevalensi penduduk Indonesia yang didiagnosis Tuberkulosis oleh tenaga kesehatan tahun 2007 dan 2013 tidak berbeda yaitu sebesar $0,4 \%{ }^{2}$ Berbagai upaya program pengendalian Tuberkulosis paru dilakukan pemerintah melalui Kementrian Kesehatan salah satunya adalah TOSS Tuberkulosis (Temukan Tuberkulosis Obati Sampai Sembuh) yang diperkenalkan dan dilakukan sejak 2016. Dalam menangani masalah Tuberkulosis paru ini baik secara global maupun di Indonesia selalu menemui hambatan.

Hambatan yang ditemui dalam proses pengobatan penderita Tuberkulosis adalah masih adanya penderita yang tidak patuh dalam minum obat. Tingkat kepatuhan penggunaan obat pada klien Tuberkulosis di Kabupaten Kerinci bahwa $55,56 \%$ patuh minum obat. ${ }^{3}$ Kepatuhan berobat klien Tuberkulosis di daerah Ciomas Bogor berkisar pada angka $74 \%$. Ketidakpatuhan terhadap pengobatan akanmenyebabkan semakin banyak ditemukan penderita Tuberkulosis. ${ }^{4}$ Multi Drug Resisten (TB MDR). Hal ini tentunya akan mempersulit pemberantasan penyakit Tuberkulosis paru di Indonesia serta memperberat beban pemerintah. ${ }^{1}$

Tuberkulosis Multi Drug Resisten (TB MDR) pada dasarnya adalah suatu fenomena buatan manusia, sebagai akibat dari pengobatan klien Tuberkulosis yang tidak adekuat dan penularan dari klien TB MDR tersebut. Di tingkat global Indonesia berada di peringkat 8 dari 27 negara dengan perkiraan klien TB MDR di Indonesia sebesar 6.900 , yaitu $1,9 \%$ dari kasus baru dan $12 \%$ dari kasus pengobatan ulang. ${ }^{5}$ Suatu tindakan yang serius yang dapat dilakukan untuk menekan atau mencegah terjadinya TB MDR yaitu dengan suatu pengawasan terhadap kepatuhan meminum obat agar penderita Tuberkulosis mampu minum obat sesuai program dan akan mencegah terjadinya TB MDR.

Pengawasan terhadap kepatuhan minum obat adalah tugas dari Pengawas Menelan Obat (PMO). Ada hubungan yang kuat antara peran PMO dengan kepatuhan minum obat pada penderita Tuberkulosis Paru. ${ }^{6}$ Faktor-faktor yang mempengaruhi terjadinya TB MDR adalah salah satunya faktor klien yaitu tidak adanya PMO atau PMO kurang baik. ${ }^{7}$

Aspek yang dapat menjadikan PMO mempunyai arti penting untuk klien Tuberkulosis adalah dukungan. Dalam hal ini dukungan sebagai PMO dapat lebih efektif dilakukan oleh keluarga. Dukungan yang kuat pada penderita terutama dari pihak keluarga akan sangat membantu proses penyembuhan penyakit Tuberkulosis misalnya dalam meningkatkan kepatuhan pengobatan dengan cara pengawasan dalam menelan obat serta pemberian semangat pada penderita. Ada hubungan antara dukungan keluarga dengan kepatuhan minum obat. Dari seluruh responden yang memiliki dukungan keluarga tinggi tidak ada yang tidak patuh minum obat, dan ada 1 orang yang memiliki dukungan keluarga rendah dan klien tersebut tidak patuh minum obat. ${ }^{8}$

Begitu juga dengan peran keluarga sebagai PMO. Keluarga dapat menjadi PMO yang efektif, hal ini karena keluarga bertanggung jawab untuk memastikan klien dengan TB meminum OAT sesuai 
anjuran. Menurut dr Kusnadi (2016) dalam keterangannya kepada wartawan pojok jabar, pengawasan orang terdekat sangat penting, agar klien minum obat selama enam bulan secara konsisten. 94,44\% semua subjek memiliki PMO dan responden menyatakan bahwa PMO selalu mengingatkan responden untuk minum obat dan mengecek dahak tepat waktu, serta menegur apabila tidak minum obat. $^{9}$

Hasil dari pengamatan yang dilakukan bahwa jumlah penderita Tuberkulosis di daerah Puskesmas Bogor Barat, yang terbanyak salah satunya adalah di Puskesmas Gang Kelor. Kemudian peneliti melakukan studi pendahuluan di salah satu puskesmas di Bogor Barat yaitu di Puskesmas Gang Kelor. Hasil wawancara dengan petugas puskesmas bahwa program PMO masih berjalan dan hampir semua PMO adalah berasal dari keluarga penderita Tuberkulosis itu sendiri.

Data dari Puskesmas Gang Kelor juga selama 2016-2017 terdapat 1 penderita TB MDR dan 2 kasus penderita dengan pengobatan ulang, hal ini menggambarkan bahwa meskipun PMO sudah dilatih tetapi pada wilayah kerja puskesmas gang kelor masih terjadi TB MDR, sehingga ancaman terhadap penyakit TB MDR sangat mungkin terjadi pada penderita Tuberkulosis yang belum menderita penyakit TB MDR, oleh karena itu dukungan dan peran keluarga sangat diperlukan untuk mencegah terjadinya TB MDR. Berdasarkan uraian diatas peneliti tertarik untuk mengambil judul Gambaran Dukungan Dan Peran Keluarga Sebagai PMO Dalam Pencegahan TB MDR.

\section{METODE}

Penelitian ini menggunakan desain penelitian deskriptif, dimanapeneliti hanya mendapatkan gambaran dukungan keluarga dan peran keluarga sebagai PMO dalam mencegah TB
MDR.Penelitian ini dilaksanakan oleh peneliti di wilayah kerja Puskesmas Gang Kelor. Pada penelitian ini yang dijadikan populasi adalah keluarga dari penderita TB yang berperan sebagai Pengawas Minum Obat (PMO), yaitu sebanyak 35 responden. Apabila subyeknya kurang dari 100 maka lebih baik diambil semua ${ }^{10}$, maka dalam hal ini peneliti mengambil total populasi.

Kriteria sampel yang dibutuhkan secara inklusi. Keluarga (bapak/ibu/kakak/adik) dari penderita TB yang ditunjuk Puskesmas sebagai PMO yang tinggal serumah dengan klien, memahami bahasa Indonesia, dapat menulis dan membaca, bersedia menjadi responden. Adapun kriteria secara eksklusi yaitu $\mathrm{PMO}$ yang sedang sakit parah, PMO dari penderita yang sudah mengidap penyakit TB MDR, PMO yang sedang tidak ada rumah lebih dari batas pengumpulan data, keluarga yang mempunyai anggota keluarga TB Paru, tetapi tidak berobat ke Puskesmas Gang Kelor Kota Bogor.

Teknik pengumpulan data dalam penelitian ini adalah menggunakan teknik angket dengan bentuk pertanyaan yang terstruktur melalui kuesioner. Sumber data berasal dari data primer dan data sekunder. Adapun pengolahan dan analisis data dalam penelitian ini terdiri dari penyuntingan data, pengkodean, memasukkan data, tabulasi, kemudian pembersihan data. Apabila semua data dari setiap sumber data atau responden selesai dimasukkan, perlu dicek kembali untuk melihat kemungkinan-kemungkinan adanya kesalahan-kesalahan kode, ketidaklengkapan, dan sebagainya. Kemudian dilakukan pembetulan atau koreksi.

Analisa yang digunakan peneliti adalah analisis univariat. Karakteristik yang dianalisis antara lain : jenis kelamin, umur, pekerjaan, pendidikan, dan penghasilan. Untuk variabel dukungan keluarga menggunakkan skala Likert dan 
diinterpretasikan berdasarkan distribusi ferekuensi nilai median. Kemudian dikategorikan dukungan keluarga baik, dukungan keluarga kurang. Begitu juga dengan peran keluarga, keluarga berperan dengan baik dan keluarga tidak berperan dengan baik.

\section{HASIL}

a. Jenis kelamin

Diagram 5.1. Distribusi Frekuensi Responden Berdasarkan Jenis kelamin Di Wilayah Kerja Puskesmas Gang Kelor Kota Bogor Pada Tahun 2017 ( $n=35)$

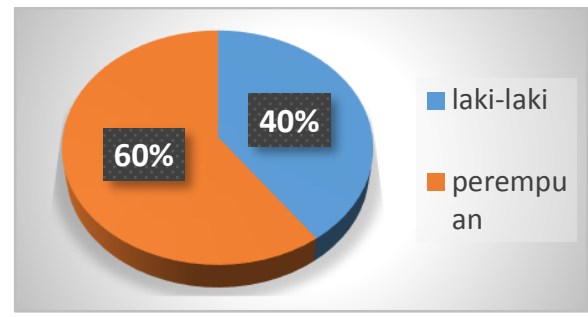

Berdasarkan diagram 5.1, lebih dari setengah responden yaitu sebanyak 21 orang $(60 \%)$ berjenis kelamin perempuan dan kurang dari setengah responden yaitu sebanyak 14 orang (40\%) berjenis kelamin laki-laki. Penelitian ini di dominasi oleh perempuan

b. Umur

Diagram 5.2. Distribusi Frekuensi Responden Berdasarkan Umur Di Wilayah Kerja Puskesmas Gang Kelor Kota Bogor Tahun 2017 ( $n=35)$

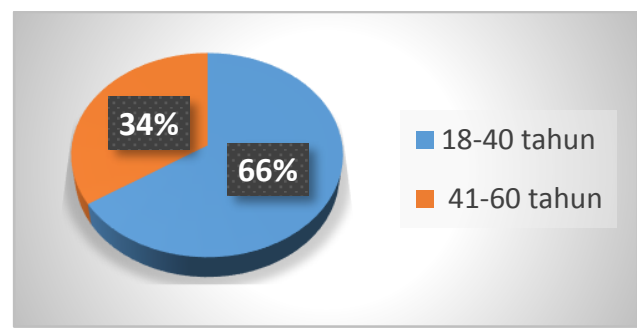

Berdasarkan diagram 5.2, menunjukan lebih dari setengah responden yaitu sebanyak 23 orang (66\%) berumur 18-40 tahun dan kurang dari setengah responden yaitu sebanyak 12 orang (34\%) berumur 41-60 tahun. Responden dalam penelitian ini di dominasi umur 1840 tahun.

c. Status Pekerjaan

Diagram 5.3. Distribusi Frekuensi Responden Berdasarkan Status Pekerjaan Di Wilayah Kerja Puskesmas Gang Kelor Kota Bogor Tahun 2017 $(n=35)$.

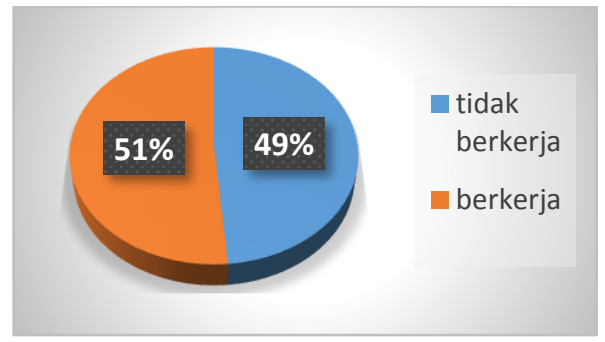

Berdasarkan diagram 5.3, menunjukan lebih dari setengah responden yaitu sebanyak 18 orang (51\%) memiliki pekerjaan dan kurang dari setengah responden yaitu sebanyak 17 orang (49\%) tidak bekerja. Responden dalam penelitian ini didominasi oleh responden yang berkerja (PNS, pegawai swasta, wiraswasta, buruh, dan lain-lain).

d. Pendidikan

Diagram 5.4. Distribusi Frekuensi Responden Berdasarkan Pendidikan Di Wilayah Kerja Puskesmas Gang Kelor Kota Bogor Tahun 2017 ( $\mathrm{n}=35)$

\begin{tabular}{|l|c|c|}
\hline \multicolumn{1}{|c|}{ Pendidikan } & $\mathrm{n}$ & $\%$ \\
\hline Tidak sekolah & 0 & $0 \%$ \\
\hline SD & 6 & $20 \%$ \\
\hline SMP & 11 & $31 \%$ \\
\hline SMA & 14 & $37 \%$ \\
\hline Perguruan Tinggi & 4 & $11 \%$ \\
\hline
\end{tabular}

Berdasarkan diagram 5.4, menunjukan kurang dari setengah responden yaitu sebanyak 14 orang (37\%) memiliki pendidikan SMA dan tidak ada satupun responden yang tidak sekolah. Responden dalam penelitian ini didominasi oleh pendidikan SMA.

e. Penghasilan 
Diagram 5.5. Distribusi Frekuensi Responden Berdasarkan Penghasilan Di Wilayah Kerja Puskesmas Gang Kelor Kota Bogor Tahun $2017(\mathrm{n}=35)$

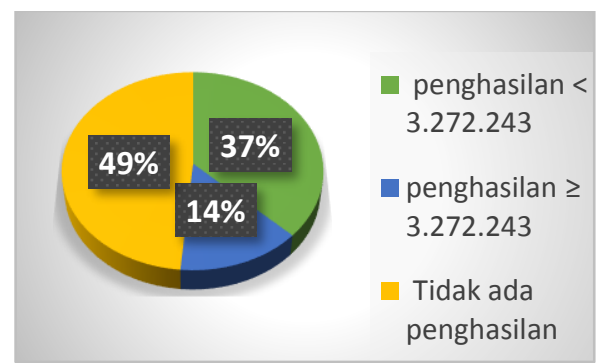

Berdasarkan diagram 5.5, menunjukan kurang dari setengah responden yaitu sebanyak 17 orang (49\%) tidak memiliki penghasilan dan sebagian kecil responden yaitu sebanyak 5 orang (14\%). memiliki penghasilan $\geq$ Rp. 3.272.243. Responden dalam penelitian ini didominasi oleh responden yang tidak memiliki penghasilan (tidak berkerja).

f. Dukungan Keluarga

Diagram 5.6. Distribusi Frekuensi Responden Berdasarkan Dukungan Keluarga Sebagai PMO Dalam Pencegahan TB MDR Di Wilayah Kerja Puskesmas Gang Kelor Kota Bogor Tahun $2017(\mathrm{n}=35)$

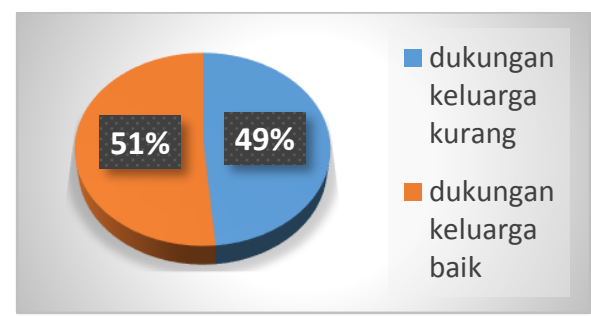

Berdasarkan diagram 5.6, menunjukan lebih dari setengah responden yaitu 18 orang (51\%) memiliki dukungan baik sebagai $\mathrm{PMO}$ dalam pencegahan TB MDR dan kurang dari setengah responden yaitu sebanyak 17 orang (49\%).Memiliki dukungan kurang sebagai PMO dalam pencegahan TB MDR. Penelitian ini didominasi oleh dukungan keluarga yang baik sebagai PMO dalam pencegahan TB MDR. g. Peran Keluarga

Diagram 5.7. Distribusi Frekuensi Responden Berdasarkan Peran Keluarga Di Wilayah Kerja Puskesmas Gang Kelor Kota Bogor Tahun $2017(\mathrm{n}=35)$

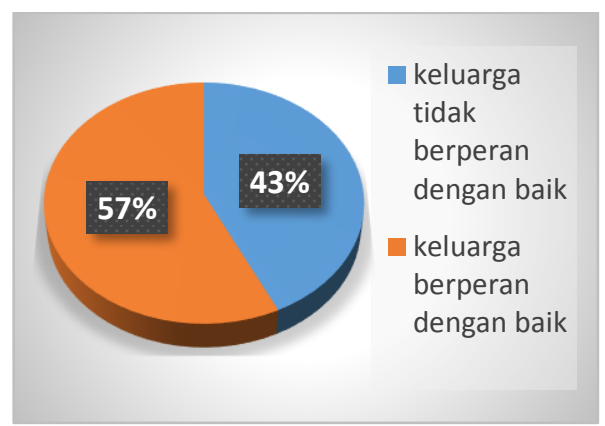

Berdasarkan diagram 5.7, menunjukan lebih dari setengah responden yaitu sebanyak 20 orang (57\%) berperan dengan baik sebagai PMO dalam pencegahan TB MDR dan kurang dari setengah responden yaitu sebanyak 15 orang (43\%) tidak berperan dengan baik sebagai PMO dalam pencegahan TB MDR. Penelitian ini didominasi oleh responden yang berperan dengan baik sebagai PMO dalam pencegahan TB MDR.

\section{PEMBAHASAN}

Hasil dari penelitian ini menggambarkan proporsi terbesar dukungan keluarga sebagai PMO dalam pencegahan terjadinya TB MDR adalah baik. Dukungan keluarga adalah sikap, tindakan dan penerimaan keluarga terhadap penderita yang sakit. ${ }^{11}$ Dukungan keluarga merupakan bantuan yang dapat diberikan kepada keluarga lain berupa barang, jasa, informasi dan nasehat, yang mana membuat penerima dukungan akan merasa disayangi, dihargai, dan tentram. ${ }^{12}$

Ada hubungan antara dukungan keluarga dengan kepatuhan minum obat. Dari seluruh responden yang memiliki dukungan keluarga yang tinggi tidak ada yang tidak patuh minum obat, terdapat 
satu orang yang memiliki dukungan keluarga rendah dan klien tersebut tidak patuh minum obat. ${ }^{13}$ Pencegahan terhadap terjadinya Tuberkulosis Multi Drug Resisten (TB MDR) menurut Erlina Burhan (2010) salah satunya adalah Integrasi Program DOTS. Faktor-faktor yang mempengaruhi terjadinya TB MDR adalah salah satunya faktor klien yaitu tidak adanya PMO atau PMO kurang baik. ${ }^{14}$

Di Puskesmas Gang Kelor program DOTS terkait PMO masih berjalan dan responden yang berperan sebagai $\mathrm{PMO}$ mengetahui tentang risiko terjadinya TB MDR. Lebih dari setengah keluarga sebagai PMO sudah berupaya agar tidak terjadi TB MDR dan kurang dari setengah PMO meskipun telah dilatih sebagai PMO dan sudah mengetahui risiko terjadinya TB MDR tetapi tetap mempunyai dukungan keluarga yang kurang dalam mencegah terjadinya TB MDR. Hasil penelitian yang didapatkan bahwa sebanyak 18 orang (51\%) responden yang mempunyai dukungan yang baik adalah responden yang menerima penyakit yang dialami oleh penderita TB, dan 17 orang (49\%) responden yang mempunyai dukungan kurang, disebabkan karena kurang adekuatnya dukungan yang diberikan berupa dukungan emosional seperti memberikan semangat dan penerimaan terhadap penderita TB, dukungan informasi seperti informasi tentang penyakit TB maupun dukungan instrumental yaitu responden tidak mengantar klien untuk berobat atau membiarkan klien untuk berobat sendiri ke puskesmas. Hal ini terjadi karena beberapa faktor yang mempengaruhi dukungan keluarga sebagai PMO itu sendiri.

Faktor-faktor yang mempengaruhi dukungan keluarga salah satunya adalah kelas sosial ekonomi orang tua. Kelas sosial ekonomi disini meliputi tingkat pendapatan, pekerjaan orang tua dan tingkat pendidikan. ${ }^{11}$ Hasil penelitian dari
35 responden berdasarkan status pekerjaan, bahwa kurang dari setengah responden yaitu sebanyak 17 orang (49\%) tidak bekerja dan lebih dari setengah responden yaitu sebanyak 18 orang (51\%) memiliki pekerjaan. Penelitian ini didominasi oleh responden yang berkerja, dikarenakan kurang dari setengah responden yaitu sebanyak 15 orang (43\%) berperan sebagai PMO dan berperan sebagai suami, sehingga hampir seluruhnya berkerja. Presentase tertinggi kurangnya dukungan keluarga berada pada responden yang tidak berkerja yaitu sebanyak 10 orang (29\%) dan dukungan keluarga yang baik berada pada responden yang berkerja yaitu sebanyak 11 orang (31\%).

Hal ini sejalan dengan teori Friedman (2010) bahwa responden yang tidak bekerja atau keluarga kelas bawah mempunyai tingkat dukungan yang lebih rendah dibandingkan responden yang mempunyai pekerjaan. Orang yang memiliki pekerjaan yang lebih layak guna pemenuhan semua kebutuhan hidupnya juga memiliki kecenderungan untuk memiliki tingkat kesehatan dan perilaku kesehatan yang lebih baik dari pada orang yang memiliki tingkat pekerjaan yang lebih rendah dengan asumsi memiliki kebutuhan hidup yang sama, oleh sebab itu seseorang yang memiliki pekerjaan yang layak akan lebih memperhatikan perilaku kesehatan untuk diri sendiri dan lingkungannya. ${ }^{1}$

Pendidikan juga merupakan faktorfaktor yang mempengaruhi dukungan keluarga. Tingkat pendidikan seseorang akan berpengaruh dalam memberi respon terhadap sesuatu yang datang dari luar. Pendidikan dapat mempengaruhi seseorang termasuk juga perilaku seseorang termasuk juga perilaku seseorang akan pola hidup, terutama dalam memotivasi sikap dan berperan serta dalam perkembangan kesehatan. ${ }^{1}$ Berdasarkan hasil penelitian dari 35 responden didapatkan data bahwa kurang 
dari setengah responden yaitu sebanyak 14 orang (37\%) memiliki pendidikan SMA dan tidak ada satupun responden yang tidak sekolah. Responden dalam penelitian ini didominasi oleh pendidikan SMA.

Didapatkan juga data tentang dukungan keluarga yang dipengaruhi oleh pendidikan. Jumlah responden dengan dukungan keluarga baik berada pada responden yang berpendidikan SMA yaitu sebanyak 8 orang (24\%). Hal ini sesuai dengan teori yang dikemukakan Depkes RI (2007), bahwa pendidikan berpengaruh terhadap dukungan yang diberikan kepada seseorang, semakin tinggi pendidikan seseorang maka semakin tinggi pula pemikiran seseorang dalam bertindak termasuk dalam hal ini memberikan atau memotivasi penderita TB agar tidak terjadi TB MDR.

Penghasilan juga berpengaruh terhadap dukungan keluarga, karena dalam keluarga dengan kelas sosial menengah mempunyai tingkat dukungan, afeksi dan keterlibatan yang lebih tinggi daripada keluarga dengan kelas sosial bawah. ${ }^{11}$ Berdasarkan data yang didapatkan bahwa dukungan keluarga kurang terhadap pencegahan TB MDR terbanyak berada pada responden yang tidak memiliki penghasilan. Berdasarkan pengamatan yang dilakukan, keluarga yang tidak memiliki penghasilan tidak memberikan dukungan instrumental (mengantar berobat penderita Tuberkulosis paru). karena responden sendiri sebagai sumber dukungan bagi klien tidak dapat memenuhi kebutuhannya sendiri.

Peran Keluarga

Hasil dari penelitian ini menggambarkan bahwa proporsi terbesar peran keluarga adalah keluarga berperan dengan baik dalam pencegahan TB MDR. Peran keluarga menggambarkan seperangkat perilaku interpersonal, sifat, kegiatan yang berhubungan dengan individu dalam posisi dan situasi tertentu. ${ }^{15}$ Dalam hal ini peran keluarga pada penderita TB, menjalankan perannya sebagai pemberi perawatan kepada anggota keluarga yang menderita Tuberkulosis, misalnya keluarga mengingatkan atau memonitor waktu minum obat, mengontrol persediaan obat, mengantarkan penderita kontrol, memisahkan alat-alat penderita dengan anggota keluarga yang lain, meningkatkan kesehatan lingkungan penderita, dan pemenuhan kebutuhan psikologis agar penderita tidak merasa terisolir dalam lingkungannya. ${ }^{16}$

Penelitian ini juga didukung oleh penelitian yang dilakukan oleh Jufrizal dan Mulyadi (2016), menyatakan bahwa $79,4 \%$ keluarga berperan baik dalam keberhasilan pengobatan pada klien TB paru. Rendahnya kepatuhan minum obat dapat berakibat pada resistensi Mycobacterium Tuberculosa. Pasien yang tidak teratur minum obat memiliki risiko munculnya drug resistant-tuberculosis (DR-TB). ${ }^{9}$

Penelitian yang dilakukan sesuai dengan teori Widiastuti (2009), karena sebagian besar responden yaitu sebanyak 20 responden (57\%) yang berperan baik sebagai PMO selalu menjalankan tugasnya seperti mengambil obat jika klien tidak bisa mengambil obat di puskesmas, mengingatkan klien minum obat dan menemani klien untuk berobat. $\mathrm{Hal}$ ini dilakukan agar tidak terjadi kebal obat atau TB MDR, dan kurang dari setengah responden yaitu 15 responden (43\%) berperan tidak baik sebagai PMO dalam pencegahan TB MDR hal ini dikarenakan berbagai faktor.

Faktor yang mempengaruhi peran salah satunya adalah perbedaan kelas social. ${ }^{11}$ Dalam penelitian ini didapatkan data peran keluarga yang dipengaruhi tingkat penghasilan bahwa penghasilan > 3.272.243 dan < 3.272.243 sama-sama tidak memberikan peran dengan baik. Dari hasil penelitian tentang peran yang dipengaruhi tingkat penghasilan, dapat 
dinyatakan bahwa, berperan baik atau tidak berperan baik keluarga sebagai PMO tidak ada kaitannya dengan penghasilan

Hal ini sejalan dengan penelitian yang dilakukan bahwa pekerjaan dan pendapatan seseorang tidak berpengaruh dengan keberhasilan pengobatan. Keluarga yang berpenghasilan tinggi maupun rendah tidak berpengaruh karena pengobatan untuk pasien TB paru di subsidi oleh pemerintah lewat puskesmas, sehingga pengobatan klien TB diberikan gratis tanpa memandang pekerjaan, responden yang tidak mempunyai penghasilan tinggi maupun rendah akan mendapatkan pelayanan yang sama. ${ }^{17}$ Pada penelitian ini juga klien TB mendapatkan biaya pengobatan dari Puskesmas Gang Kelor sehingga responden yang mempunyai penghasilan $>3.242 .243$ atau $<3.242 .243$ tidak berpengaruh terhadap perannya sebagai PMO dalam pencegahan TB MDR.

Jenis kelamin PMO ikut berperan dalam penentuan tingkat keberhasilan dalam menjalankan tugas dan fungsinya. ${ }^{18}$ Berdasarkan hasil penelitian yang dilakukan, didapatkan data lebih dari setengah responden yaitu sebanyak 20 orang $(57 \%)$ berjenis kelamin perempuan dan kurang dari setengah responden yaitu sebanyak 15 orang (43\%) berjenis kelamin laki-laki. Perbedaan jati diri antara pria dan wanita mempengaruhi produktivitas kerja individu. Pria akan membanggakan dirinya atas kemampuan memecahkan masalah atau menyelesaikan sebuah pekerjaan, sedangkan wanita lebih mementingkan rasa kepedulian, integritas, dan nilai-nilai yang lebih personal dan kepedulian untuk melayani. ${ }^{18}$

Angka kejadian TB pada jenis kelamin laki-laki cenderung lebih tinggi dibandingkan perempuan hal ini diakibatkan gaya hidup laki-laki cenderung lebih banyak merokok dimana merokok dapat memperparah penyakit
Tuberkulosis. ${ }^{19} \mathrm{Hal}$ ini sejalan dengan penelitian yang dilakukan, dimana penderita TB lebih banyak terjadi pada laki-laki sehingga peran PMO lebih banyak dijalankan oleh perempuan. Selain itu perempuan sebagai PMO juga mendukung dalam hal perhatian dan kesempatan untuk mendampingi penderita.

Faktor yang mempengaruhi peran selanjutnya adalah umur. Umur adalah usia yang secara garis besar menjadi indikator dalam kedewasaan dalam setiap pengambilan keputusan yang mengacu pada setiap pengalamannya. Semakin cukup umur, tingkat kematangan dan kekuatan seseorang akan lebih matang dalam berfikir dan logis. ${ }^{1}$ Berdasarkan hasil penelitian yang dilakukan, didapatkan data sebagian besar responden yaitu 23 orang (66\%) berumur 18-40 tahun. Dalam menjalankan tugasnya seorang PMO diharapkan memiliki umur yang cukup dewasa sehingga dalam melakukan pendampingan terhadap penderita tuberkulosis, dapat menganalisis setiap permasalah yang timbul dan memberikan solusi secara cepat dan tepat. ${ }^{1}$

\section{KESIMPULAN}

1. Karakteristik responden sebagian besar berusia 18-40 tahun, lebih dari setengah responden bekerja, kurang dari setengah responden memiliki pendidikan SMA dan kurang dari setengah responden tidak memiliki penghasilan.

2. Dukungan keluarga sebagai $P M O$ dalam pencegahan terjadinya TB MDR didapatkan data lebih dari setengah responden memberikan dukungan baik sebagai PMO dalam pencegahan TB MDR.

3. Peran keluarga sebagai PMO dalam pencegahan terjadinya TB MDR didapatkan data lebih dari setengah 
responden berperan dengan baik dan kurang dari setengah responden tidak

\section{DAFTAR PUSTAKA}

1.

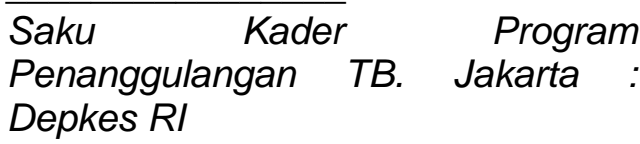

2. Kementrian Kesehatan Republik Indonesia. 2015. Rencana Strategis Kementrian Kesehatan. www.depkes.go.id/resources/downlo ad/info-publik/Renstra-2015.pdf.

3. Pameswari, Puspa., Halim, Auzal., Yustika, Lisa. 2016. Tingkat Kepatuhan Penggunaan Obat Pada Pasien Tuberkulosis di Rumah Sakit Mayjen H.A.Thalib Kabupaten Kerinci. Jurnal Sains Farmasi dan Klinis, 2 (2), 116-121. Jsfkonline.org/index.php/jsfk/article/d ownload/ 60/pdf. Diakses pada tanggal 24 Februari 2017, 18:38 WIB

4. Kotouki, Anance. 2012. Gambaran perilaku penderita dan resiko Tuberkulosis BTA Positif dengan kepatuhan minum obat dan kebiasaan membuang dahak di wilayah puskesmas ciomas kabupaten bogor. Skripsi open, Universitas Indonesia. Jakarta.

5. WHO. 2016. Global Tuberculosis Report 2016.

http://www.who.int/tb/publications /global_report /en?diakses pada tanggal 23 Februari 2017, 07:10

6. Kartikasari, Dewi., Rejeki, Sri., Wuryanto, Edy. 2012. Hubungan Peran Keluarga Sebagai Pengawas Minum Obat (PMO) dengan Kepatuhan Minum Obat Pada Penderita TB Paru. Jurnal Keperawatan, Vol 5 : 71-79. http://jurnal.unimus.ac.id/index.php/F IKkeS/article/view/1861. Diakses pada tanggal 22 Februari 2017, 10.55 WIB berperan dengan baik sebagai PMO dalam pencegahan TB MDR.

7. Soepandi, Priyanti Z. 2010. Diagnosis dan Faktor Yang Mempengaruhi Terjadinya TB-MDR. https://agus34drajat.files.wordpress.c om/2010/10/jurnal-tuberkulosisindonesia-vol7-okt2010.pdf. Diakses pada tanggal 21 Februari 2017, 17.20 WIB

8. Purhadi dan Riniasih, Wahyu. 2015. Hubungan Dukungan Sosial Keluarga Sebagai PMO dengan Kepatuhan Minum Obat Pada Fase Intensif Penderita TBC. Jurnal, Volume 01 : 01-09. http://ejournal.annurpurwodadi.ac.id/i ndex.php /TSCDSKep/article/view/65/69.

Diakses pada tanggal 9 Maret 2017 22.00 WIB

9. Dhiyantari, Ni Putu., dkk, 2014. Gambaran Kepatuhan Minum Obat Pada Penderita Tuberkulosis Paru di Wilayah Kerja Puskesmas Bebandem, Karangasem. http://ojs. unud.ac.id/index.php/eum/article/vie w/11928/8234. Diakses pada tanggal 26 Februari 2017 10:50 WIB

10. Arikunto. 2010. Prosedur Penelitian Suatu Pendekatan Praktik. Jakarta: Rineka Cipta

11. Friedman, Marilyn M. 2010. Buku Ajar Keperawatan Keluarga. Jakarta : EGC

12. Taylor, Shelley E., Peplau, Letitia A., Sears, David O. 2009. Psikologi Sosial (edisi ke dua belas). Jakarta : Prenada Media Group

13. Purhadi dan Riniasih, Wahyu. 2015. Hubungan Dukungan Sosial Keluarga Sebagai PMO dengan Kepatuhan Minum Obat Pada Fase Intensif Penderita TBC. Jurnal, Volume 01 : 01-09. http://ejournal.annurpurwodadi.ac.id/i 
ndex.php

/TSCDSKep/article/view/65/69.

Diakses pada tanggal 9 Maret 2017 22.00 WIB

14. Soepandi, Priyanti Z. 2010. Diagnosis dan Faktor Yang Mempengaruhi Terjadinya TB-MDR. https://agus34drajat.files.wordpress.c om/2010/10/jurnal-tuberkulosisindonesia-vol7-okt2010.pdf. Diakses pada tanggal 21 Februari 2017, 17.20 WIB

15. Setiawan, Ridwan. 2016. Teori dan Praktek Keperawatan Keluarga. Semarang : Unnes Press

16. Widiastuti, Retno dan Isnaeni, Yuli. 2009. Peran Keluarga Dalam Merawat Anggota Keluarga Yang Menderita Tuberkulosis Paru Di Wilayah Kerja Puskesmas Wirobrajan Yogyakarta. Skripsi, PSIK Aisyiyah Yogyakarta. http://opac.uni sayogya.ac.id/1789/1/NASPUB.pdf diakses pada tanggal 06 April 2017, 19.00 WIB
17. Harnanik. 2014. Analisis FaktorFaktor Yang Mempengaruhi Keberhasilan Pengobatan TB Paru di Puskesmas Purwodasi II Kabupaten Grobogan. STIKES Aisyiyah. http://opac.unisayogya.ac.id/342/1/N ASKAH\%20PUBLIKASI.pdf. Diakses pada tanggal 09 juli 2017, 17.00 WIB

18. Maulana, Haqi. 2011. Gambaran Pengawas Menelan Obat (PMO) di Puskesmas Genuk dan Bangetayu Semarang. Skripsi, http://jurma.unimus.ac.id/index.php /perawat/ article/download/30146/2161. Diakses pada tanggal 6 juli 2017, 19.00 WIB

19. Public Health Agency of Canada. 2010. Tuberculosis (TB) and Tobacco Smoking. http://www.phacaspc.gc.ca/tbpc.-latb/fa-fi/tbtobaccotabag-eng.php tanggal 6 juli 2017, 18.42 WIB 